\title{
GOOGLE FORMS CAN STIMULATE CONVERSATIONS IN DISCUSSION-BASED SEMINARS? AN ACTIVITY THEORY PERSPECTIVE
}

\author{
M. J. Glover \\ International Studies Group \\ University of the Free State \\ Bloemfontein, South Africa \\ e-mail: hellomichaelspeaking@gmail.com
}

\section{ABSTRACT}

One challenge in seminar-style postgraduate courses is that some students are uncomfortable with discussing course content and concepts among their peers and in front of the lecturer in seminars. This article is a case study of the incorporation of Google Form questions into seminars in a postgraduate Economic History course, a tool intervention undertaken as a response to the challenge of some students' seminar reticence. The study explores whether the tool intervention can from students' perspectives stimulate conversation, and examines whether the objectives of the students and the lecturer were aligned in the learning activity. The article draws on two theories to frame the research: Engeström (2001) and Engeström and Sannino's (2010) third generation Activity Theory, employed to locate change-enabling contradictions and the objects of the educational activities, and Laurillard's (2002b) Conversational Framework as a theory of learning wherein students and an educator interface with mutually accessible concepts. The study draws on interview data from structured interviews with students at the end of the course. The article contends that Google Forms are assistive in stimulating conversations around core concepts, and that a quaternary contradiction emerged between the lecturer and the individual students' objects in the educational activity.

Keywords: Activity theory; education technology; learning activities

\section{INTRODUCTION}

This study uses a third generation Activity Theory (AT) analysis to examine the introduction of a new tool, namely Google Form questions, into four post graduate Economic History seminars, in a course consisting of eight seminars. Generally, the study aims to explore two things. 1) The objects towards which students in the Google Form exercises strive in relation to the objects the lecturer aims to approximate in the exercise. 2) The study explores whether the students (i.e., subjects) perceived the new tool as assisting with stimulating discussions around the core content of the seminars. In terms of theory, Laurillard's Conversation Framework is used in conjunction with third generation Activity Theory (Engeström 1987; 
2001; Engeström and Sannino 2010; Hardman 2005; Laurillard 2002a; 2002b; Murphy and Rodriguez-Manzanares 2014; Nardi 1996; Peruski and Mishra 2004). The principle source of evidence is structured interview questions answered by 87.5 per cent of the seminar students in a post course questionnaire $(n=7)$.

This article proceeds by six steps. It opens with a description of the broad context in which the Activity Systems analysed occurred. Second, there is a cursory literature review and theoretical discussion, and, third, the research questions are articulated. Fourth, the research design is described, and, fifth, the tool introduction (Google Form exercise) is cast as Activity Systems. Finally, the findings are offered, and some implications of such tool interventions for higher education are described. This article draws four conclusions, a) that AT is useful for locating and richly describing the object of an educational activity, b) AT is useful for understanding the effects of a new tool in an educational activity and c) that the new tool did in fact stimulate discussions of core content or concepts in the seminars, and d) educators can benefit from using similar interventions in discussion-based seminars.

\section{CONTEXT}

The context of the educational activity under observation is as follows. The Economic History course was an Honours level ( $4^{\text {th }}$ year) postgraduate course in the Historical Studies Department at the University of Cape Town. The course ran for one semester (half a year), was entitled Topics in South African Economic History and consisted of eight, two-hour discussion-based seminars. The seminars were guided by the lecturer and comprised in-class group work tasks, group discussions, presentations and responses to presentations by students, and some transmission style lessons by the lecturer relating to historian-relevant skills, such as administering a research project, pre-reading, and concepts relating to the structuring of academic essays. The course content revolved around two core books and supplementary readings which were assigned for each seminar. Assessment was arranged into three aspects: writing, discussion-participation, and presentations.

One new element of the course, introduced by the lecturer, was the use of Google Forms as a learning tool in four of the eight seminars. The lecturer devised a Google Form question before the seminar, and sent via email a one-click-no-sign-in-required link to the students, just before the activity was undertaken, at the outset of the seminar. The Google Form question was developed by the lecturer with an eye to soliciting students' understandings of a core concept or content of that week's seminar. The Google Form question link was compatible with Apple Mac devices, PCs, PC laptops, Tablets, and Smartphones.

In all four seminars where this exercise was undertaken all students - excluding one - had 
one of the above devices on hand and could perform the task. The one student without a device borrowed the lecturer's laptop to respond to the Google Form question.

The students were asked to write a few sentences in response to the question and click submit. The students were assured that their responses to the questions would be anonymous, and were only given three to four minutes to write their responses, thus compelling them, the students, to engage in "freewriting" (Elbow 1988, 13-15) - a process of unedited fast writing in short bursts - that was also face-saving. The lecturer then projected the answers to the Google Form question onto a large monitor in the seminar, which was clearly visible to the students. An example of the Google Form answers projected onto the monitor is depicted in Figure 1.

List two positive and two negative features of BEE from the Freund and Southall readings.

7 responses

Positives: it allowed some black ownership of capital; provided aspirant black businessmen that lacked capital with capital Negatives: capital concentrated among few black elites once ownership was transferred; it is considered a burden from international investors although they are exempt from some BEE regulations

Encourages black ownership, streamlines accessible capital. Doesn't particularly dismantle market access barriers for small business, creates loopholes for mere 'window-dressing of redress'

P1) access to capital for aspiring black capitalists P2) N1) improvements in access to black ownership have been focused mainly around mainly/only MEC industries and finance N2) higher-up elites with political capital have much easier access to 'empowerment' and financial capital than those lower down with little connections N3) not much/any help to unemployed and poorly paid

Negative: 1. Mobility for some black people but not for all, re-racialisation of the economy which could further inequality (concept of class), positive- more willingness to push for social change, promotes greater black ownership after years of white domination

Pos: There has been a shift in race makeup of large parastatals. Capital put towards black owned business. Neg: Saw the creation of a super black elite and no broader empowerment. Creation of politicians moving across to private sector- ANC connections to business sector.

positive; 1 ) it created a black middle class, which was a necessary step towards more meaningful redistribution. 2) It made white capital and black labour coordinate. Negative; 1 ) in the process of creating a black middle class it further entrenched inequality along class lines.

Figure 1: Students' Google Form responses projected onto monitor in seminar

The lecturer then either read or asked different students to read the responses from the monitor, and, after each response was read, asked the students to comment on the responses. The lecturer asked each student to comment on at least one of the responses. In Figure 1, one can see that the responses are anonymous, so that each student only knows which answer they submitted. In this way, at the outset of the seminar, each student received peer feedback on their anonymous response, in the sense that they can see what other students' answers were, and in terms of 
receiving peer commentary on their responses. The lecturer, at intervals when he discerned that a crucial aspect of the discussion was lacking, would join the class discussion to mention relevant information or expand on or clarify core concepts. Having described the study's context, this article moves to a cursory literature review and a discussion of the theory employed.

\section{LITERATURE REVIEW AND THEORY}

Activity Theory (AT) is a valuable heuristic for describing pedagogical change as it enables rich descriptions of an activity and the "processes underlying the object" when a new tool or mediating artefact enters into Activity Systems (Hardman 2005, 109).

In AT, Activity Systems are rendered so that one can analyse what occurs when new "mediating artefacts" or tools are introduced into an Activity System. Importantly, Activity Systems are objected-directed and distinguishable because each activity system has a discrete object (Kuutti 1996). The unit of analysis is the object-directed activity (see Figure 2). The "subjects" in an Activity System are the agents who work towards a goal, the "object". As the subjects work towards the "object", their striving is mediated by components of the Activity System. These components are: the division of labour, the rules, the community, tools, and the community (Engeström 1987). Together these elements comprise the Activity System.

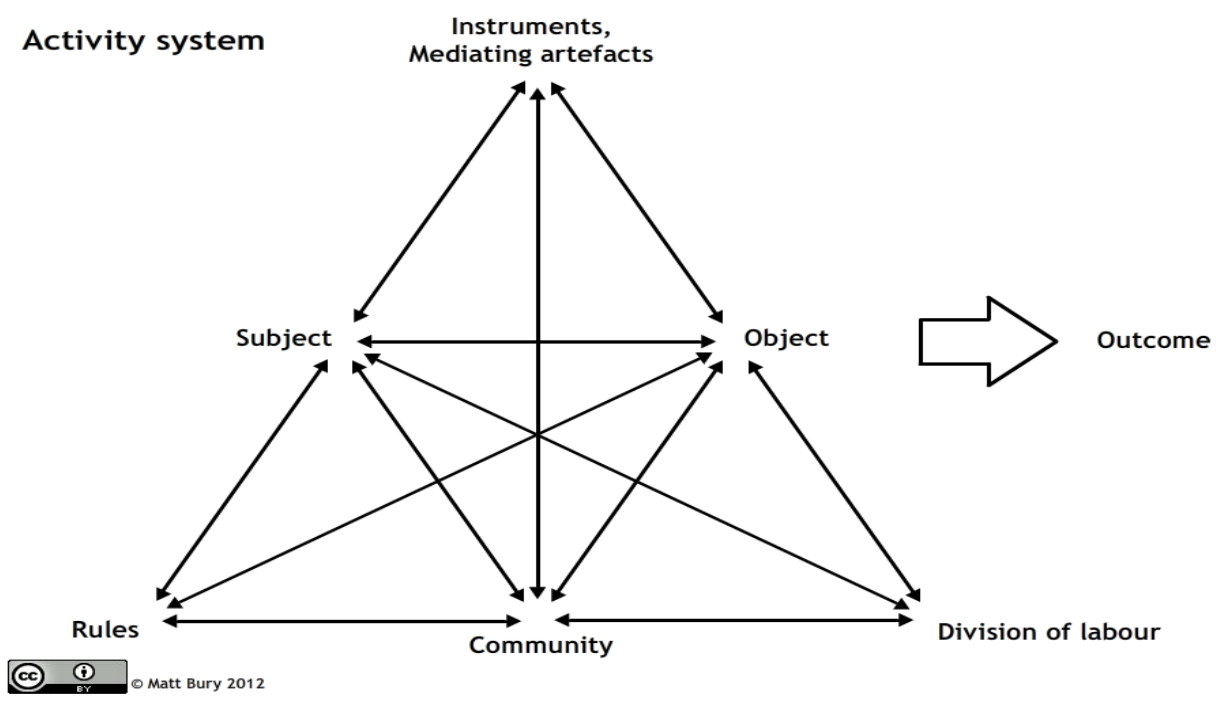

Figure 2: An Activity system

In AT, what comprises and takes place in the Activity System is the context (Nardi 1996). The subjects' motivations for striving towards an object are not exclusively internal (subjective), 
rather, motivation and the relationship between the subject and the object are mediated by components or nodes in the Activity System (Engeström 1987; 2001; Engeström and Sannino 2010).

"Contradictions" are described by third generation Activity Theory theorist Engeström as "historically accumulating structural tensions", that can dynamically occasion change which occurs between and within activity systems (Engeström 2001, 137). Contradictions can foster innovation, such as pedagogical innovation, and can enable endeavours to change the activity (Czerniewicz, Deacon, Glover and Walji 2017, 94; Engeström and Sannino 2010, 4, 5, 7, 9; Hardman 2005, 101).

Murphy and Rodriguez-Manzanares (2014) provide a strong overview of how AT has been used to specifically study pedagogical shifts after introducing new digital tools. Three studies in particular are especially germane, and show that AT can be used to analyse pedagogical shifts. One study of a mathematics teacher in a rural high school used AT to understand how computers can "transform pedagogy" (Hardman 2005, 109-110). Another study applied AT to examine collaboration between faculty members making online courses and identifying disturbances which emerged, thus providing a heuristic to track the dynamics of how new tools affected educators' pedagogies (Peruski and Mishra 2004). Murphy and Rodriguez-Manzanares (2008) found AT useful for characterising contradictions after educators transitioned to a virtual high-school classroom and found the object had shifted from controlling and teaching towards helping students to learn themselves. In other cases, AT provides a lens for describing cases where pedagogies did not change, and where new tools affected them minimally or slowly (Barab, Barnett, Yamagata-Lynch, Squire and Keating 2002; Kirkup and Kirkwood 2005; Peruski 2003; Russell and Schneiderheinze 2005). In terms of the lecturer's object, described in detail in the Activity Systems section of this article, this study draws Laurillard's theory of learning as conversation (Laurillard 2002a, 143-145; 2002b). This theory is introduced below.

Laurillard's Conversation Framework is a theory which sees learning as a conversation (Laurillard 2002b). In this study the tool introduction occurs between the students' and lecturer's conception. In the seminars the "concept[s]" are core content and concepts for that week's seminar. Figure 3 depicts where, in Laurillard's model, the tool intervention occurs. As described in the Activity Systems section of this article, the lecturer's object in part consists in increasing the interaction via discussion between the lecturer's concept and the students' concepts and each student's concept with other students' concepts. 


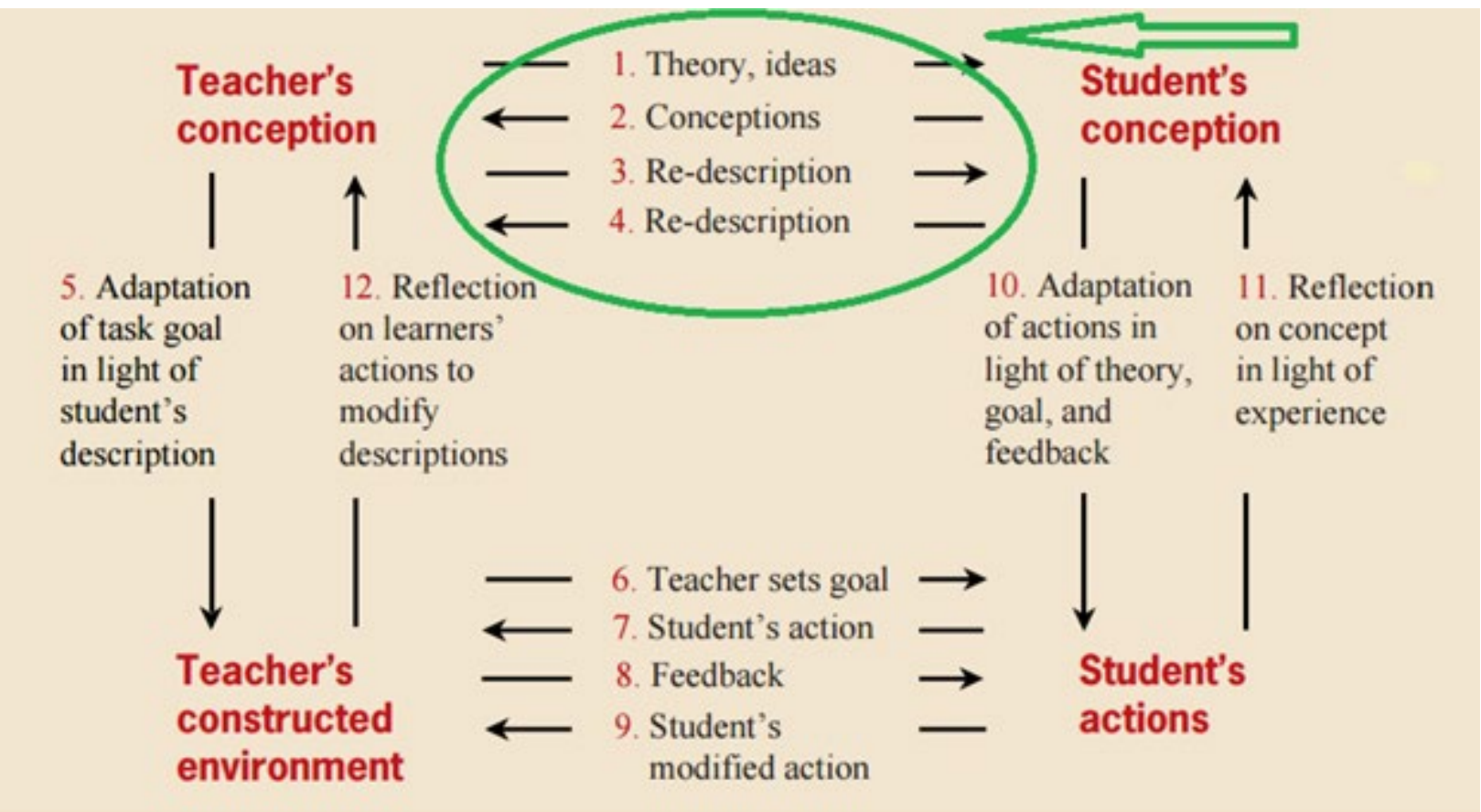

Figure 3: The iterative dialogue of Laurillard's Conversational Framework (Laurillard 2002a, 144.)

Laurillard's Conversational Framework model comprises four aspects of "learning as conversation". These are: Adaption, Discussion, Interaction, and Reflection (Laurillard 2002b). Importantly, the tool introduction in this article relates specifically to the Discussion element of Laurillard's pedagogical scenarios. The Discussion element in Laurillard's model has three aspects: discussion between the teacher and student; the teacher and the students' conception of the content is to be mutually accessible, and; in terms of learning objectives, the teacher and students should concur. The extent to which the lecturer (teacher) and the students agree on the learning objectives, the "object" in AT terms, is discussed in the Findings section of this article as it emerges as a quaternary contradiction (contradiction between interacting Activity Systems).

To sum up, AT is a useful heuristic for analysing pedagogical shifts, and thickly describing the object of an activity, and locating contradictions - this has been demonstrated by a number of studies on tool introduction in higher education settings. Further, one apposite learning theory, Laurillard's learning as conversation model, conceives of a core part of learning as the interaction between students' and teachers' conceptions. With the above theoretical underpinnings in mind, the article moves to introduce its core research questions. 


\section{RESEARCH QUESTIONS}

With the use of an Activity Theory analysis, this study focusses on two core research questions, which are formulated as follows.

1) What are the objects towards which students strive in the Google Form exercise, and does the Google Form tool facilitate striving towards their objects?

2) Does the Google Form exercise facilitate discussion between students and students, and students and lecturer, around the core concepts of the seminar?

A related aim of the study is to determine whether any contradictions emerge as a result of the tool intervention. There is an interest, in terms of how the research questionnaires were formulated, in whether there was a mismatch between what the students wanted to achieve in the Google Form exercises and what the lecturer wanted to achieve. In Activity Theory terms, there is an interest in whether there is a quaternary contradiction, a contradiction between the students' objects and the lecturer's object, since the lecturer and the students form part of discrete but neighbouring Activity Systems (see Figure 6).

\section{RESEARCH DESIGN}

The interview questions were developed with guidance from an Activity Theory Checklist devised by education psychologist and theorist Joanne Hardman (Hardman 2008, 75). In Hardman's checklist, information is to be gathered according to six Activity System concepts, namely, Outcomes, Mediating artefacts (or tools), Object, Division of labour, Community, and Rules. Hardman's checklist is reproduced in Figure 4.

\begin{tabular}{|l|l|}
\hline AT concepts & Questions to ask when analysing evaluative episodes \\
\hline Outcomes & What is produced in the episode? \\
\hline Mediating artefacts & What tool(s) is/are used? \\
\hline Object & $\begin{array}{l}\text { What is the object/focus of this episode? } \\
\text { What is the purpose of the activity for the subject? } \\
\text { What is the teacher working on? } \\
\text { Why is s/he working on it? }\end{array}$ \\
\hline Division of labour & $\begin{array}{l}\text { Who does what in this episode? } \\
\text { Who determines what is meaningful? }\end{array}$ \\
\hline Community & $\begin{array}{l}\text { What community is involved in this episode? } \\
\text { What group of people work together on the object? }\end{array}$ \\
\hline Rules & $\begin{array}{l}\text { What kinds of rules: instructional rules=evaluative rules and } \\
\text { pacing rules? } \\
\text { Social order rules=disciplinary rules and communicative } \\
\text { interaction rules }\end{array}$ \\
\hline
\end{tabular}

Figure 4: Hardman's Activity Theory checklist (Hardman 2008, 75). 
For this research, 14 questions were developed. Two interview questions related to the Outcome of the activity, four questions related to Tools, two to the Object, two to the rules, three to the Division of labour, and one question related to the Community. (See Appendix for the list of questions.)

The questionnaire was emailed to students by the lecturer after the final marks of the course were collated, and the students returned the answered questionnaire by email. Of the eight students in the course, seven replied to the post-course questionnaire, representing a sample of 87.5 per cent of total. The students' real names were pseudonymised as Jabu, Hazel, Johan, Delphi, Iggy, Aki, and Sindile.

\section{ACTIVITY SYSTEMS}

This section describes the various mediating elements or nodes of the Activity Systems under observation in this study.

Subjects: The subjects in this study's Activity Systems are the eight students and the lecturer. They each strive towards their objects.

Tools: Also known as mediating artefacts, the tools include laptops, Apple Macs, Tablets, and Smartphones. The new tools introduced into the Activity Systems are the Google Form and the monitor onto which the students' Google Form answers are projected.

Rules: The rules are those common to university course seminars and include implicit conventions such as speaking one at a time, respectful debate, arriving timeously and preparing for the seminar by conducting the required readings and assignments.

Object: The object is the "problem space" that students and the teacher are engaged with (Hardman 2008, 73). The students strive towards their own objects and the lecturer approaches his object. The Findings section of this article investigates the students' objects.

The lecturer, who conceived of introducing a new tool into the seminars, had purposive and premeditated objects for the Google Form exercise and these were described in a previous unpublished study. In short the lecturer's object in terms of the use of Google Forms consisted of three core parts: a) enhance student-student discussion, b) reduce students' time between offering conceptions and receiving feedback, and c) overcome anxieties about writing via freewriting (Glover 2017, 6, 12, 15).

The lecturer did disclose these objectives to the students, but verbally, not in the course outline or via written communication. The three main parts of the educator's broader objective follow. a) Refers to the Laurillard-inspired view that learning occurs when there is an interplay between students' and the teacher's conceptions. b) Relates to students receiving immediate feedback from their peers and the lecturer on their grasp of core material and concepts at the 
outset of the seminar, so that students do not need to wait until the following week or later to receive feedback on their written assignments on the seminar's core question or content. In terms of c) reducing anxiety about writing, the short time frame within which students have to write anonymous responses to the Google Form question (three to four minutes) was envisioned as compelling the students to disclose their understanding of core content via writing. This was imagined to be a face-saving way of compelling students to write and disclose to themselves and the lecturer their understanding of core content or concepts.

The lecturer's Activity System is below (see Figure 5). The lecturer's and the students' interacting Activity Systems are depicted (Figure 6) in the Findings section of this article, since a core concern of this study is to analyse the relationship between tool introduction and the respective objects of the lecturer and the students.

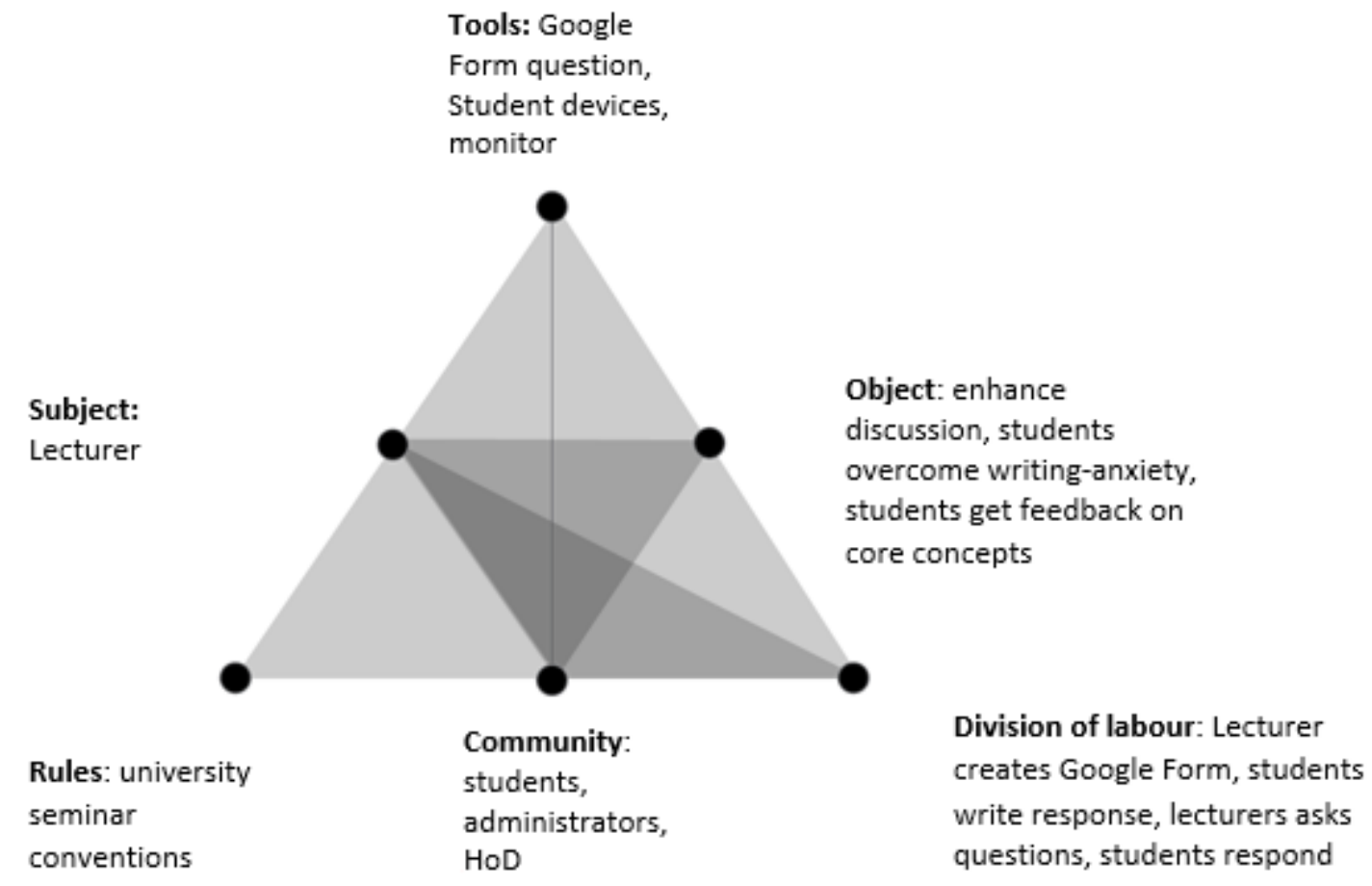

Figure 5: Lecturer's Activity System

Outcome: The outcome is what is actually achieved in the activity - a post hoc assessment of the object towards which the subjects strive.

In a study about using Google Forms to increase discussion around core concepts, written before the use of the Google Forms in the seminars, the lecture had enumerated eight anticipated or desired objects from use of the Google Forms. The outcomes were considered as follows. 
1) Lecturer and students' conceptions become mutually accessible, and the lecturer can better guide discussion.

2) Students discuss core concepts via freewriting Google Form answers.

3) Anonymity ensures students offer their conceptions in a non-threatening environment.

4) Students and lecturers can use Google Form answers as a springboard for discussion, in a way relevant to where students' conceptions are currently located.

5) Students receive immediate in-class feedback on their conceptions.

6) Students can anonymously compare their conceptions to other students' in class.

7) Students engage in freewriting and this helps overcome some writing-anxiety.

8) The short answer format implies no student can be exhaustively correct and this acts as a mechanism to neutralise competence and confidence inequalities among students. (Glover 2017, 12-13).

Community: The broader community comprises the History Department's administration staff and the Head of Department.

Division of Labour: The division of labour consists in the students preparing for the seminar in terms of reading the texts, preparing to present if it is their turn, and submitting assignments. The lecturer must be prepared at a higher level and achieve a more sophisticated grasp and command of the content and core concepts. The lecturer also apportions marks to the students for their presentations, participation in discussions, and for their written assignments. This article now discusses its findings in relation to its two principal research questions.

\section{FINDINGS}

The first research question this article considers is:

1) What are the objects towards which students strive in the Google Form exercise, and does the Google Form tool facilitate striving towards their objects?

To elicit the students' views of the object of the Google Form exercise, the following two questions were posed, "What did you think the point of the Google Form exercises was?" and, "Did you find the Google Form exercise useful? Why or why not?" (see Appendix (research instruments), questions seven and eight). The seven students who responded to the questions produced a variety of answers and all saw the object consisting in more than one element. In 
what follows this article describes the different aspects of the students' (subjects') perceptions of the object and the Google Forms' relationship to the object. It also supplies illustrative quotes from the students. All seven students considered that the Google Form exercise was useful to them and articulated some discrete and some overlapping reasons as to why the Google Form exercise was utile.

In total eight different aspects of the object of the Google Form exercise emerged (see Table 1).

Table 1: Google Form object, response frequency, and lecturer's desired outcome from tool mediation

\begin{tabular}{|c|c|c|}
\hline $\begin{array}{l}\text { Aspect of object: students' } \\
\text { perceptions }\end{array}$ & Frequency & $\begin{array}{l}\text { Lecturer's desired outcome from tool mediation of } \\
\text { object }\end{array}$ \\
\hline Ensure readings done & 3 & \\
\hline Get at core concepts & 2 & Students write about core concepts \\
\hline Write concisely about core content & 2 & Get all students to write about core content \\
\hline $\begin{array}{l}\text { Get students to see their level of } \\
\text { understanding }\end{array}$ & 1 & $\begin{array}{l}\text { Students and lecturer access students' grasp of } \\
\text { concepts }\end{array}$ \\
\hline $\begin{array}{l}\text { Lecturer gets overview of students' } \\
\text { conception }\end{array}$ & 3 & Lecturer accesses students' core concepts \\
\hline Created discussion of core concepts & 4 & $\begin{array}{l}\text { Generate discussion, student to student and students } \\
\text { to lecturer }\end{array}$ \\
\hline Express views in non-intimidating way & 1 & Write in non-threatening anonymous fashion \\
\hline Overcome "writer's block" & 3 & $\begin{array}{l}\text { Students use free writing to overcome writing-anxiety } \\
\text { Students receive immediate feedback on their } \\
\text { concepts }\end{array}$ \\
\hline
\end{tabular}

Three students thought the exercise was in part undertaken to ensure that they had conducted the seminar readings. Two students thought the exercise was to get at core concepts or content of the seminar; as one student noted, the exercise "mean[t] that the student needs to think their way through the readings and get to the gist/core of the argument" (Hazel). Two noted that the exercise compelled students to write concisely about the core concepts of the relevant seminar. Four thought part of the object was to generate discussion around core content and considered that the exercise did foster discussion of core content. Here are two ways students expressed this view. One student saw that the exercise "sparked discussion in our class and often provided alternative answers/views" (Sindile), and another remarked that it "collated ideas and created discussion around the answers to the seminar" (Delphi). In this way, a la Laurillard, an interplay between the students' concepts and the lecturer's concepts was achieved via discussion that was stimulated by the Google Form tool.

At least one student perceived the exercise enabling students to express views on core content in a way that was not intimidating, noting that is helped them to see where their "understanding of a matter was going slightly wrong in a non-intimidating environment" (Iggy). Three students thought the exercise compelled students to overcome "writer's block" (Aki) by 
having to write quickly, and one noted that the exercise helped to "understand a method of overcoming inabilities to put into words [his] thoughts" (Aki). Three noted that the exercise enabled the lecturer to get an overview of the students' grasp of core concepts of the seminar, with one student remarking that it enabled the lecturer to "get a quick, broad overview of what students were thinking with regards to one of the central questions discussed in that week's readings" (Johan). One student perceived the exercise as useful for helping him "understand exactly where I was in understanding the content at hand" (Aki).

Activity Theorist Engeström has argued that in third generation Activity Theory the model comprises at least two "minimally interacting" Activity Systems so that the objects of discrete situated Activity Systems interact to potentially create a "shared or jointly constructed object" (Engeström 2001, 136) Figure 6 casts the students qua subjects' Activity System and the lecturer's Activity System as two interacting Activity Systems. In the figure below and the table and discussion above, we can see that for each student part of their object overlaps with the lecturer's object. At least one, and in most cases two or three students articulated the value of the Google Form tool as facilitating approaching the object in a way the lecturer had conceived.

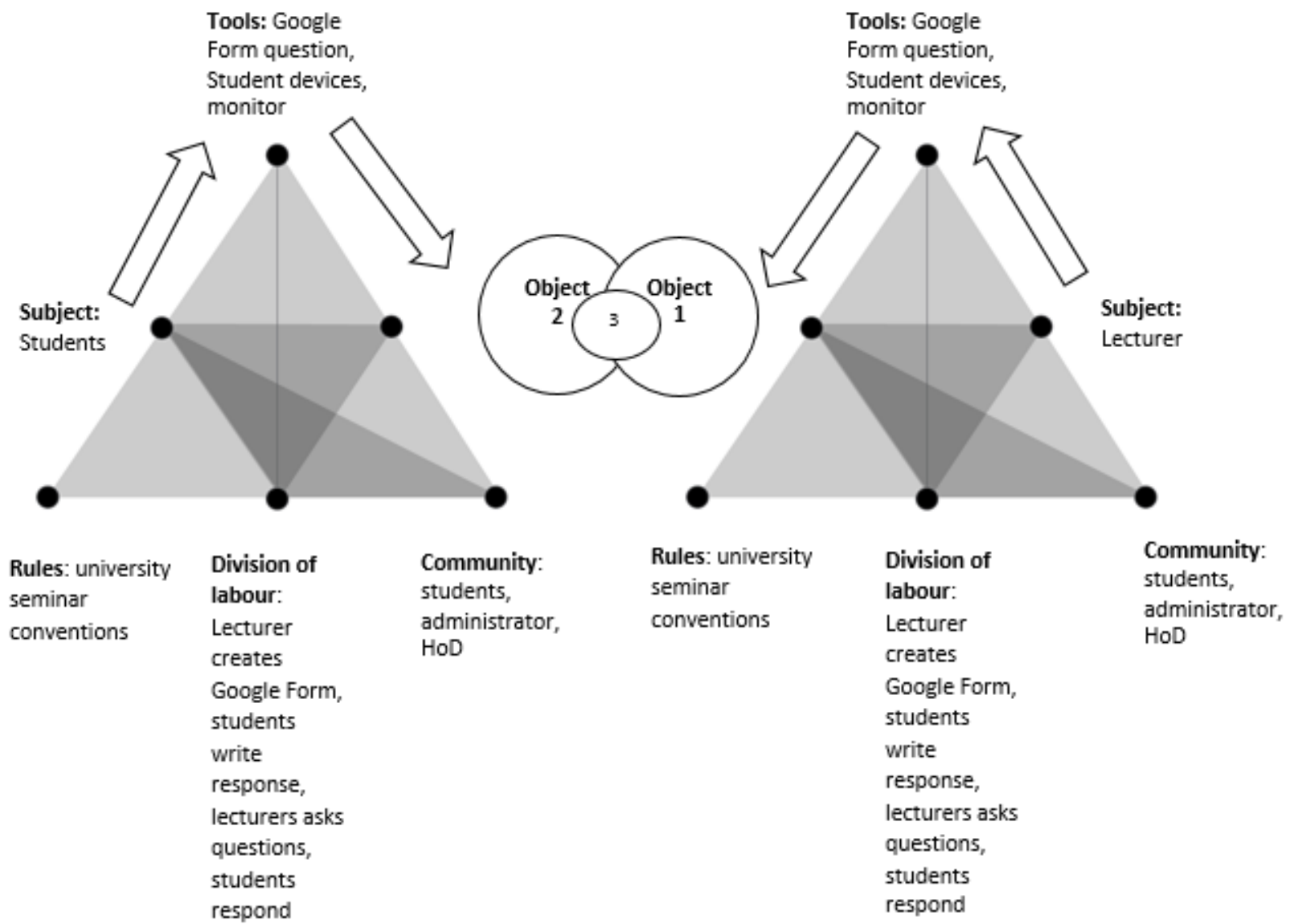

Figure 6: Lecturer and students' interacting Activity Systems 
Based on the foregoing Findings discussion and by studying Figure 6 above we can observe the presence of a quaternary contradiction, in which there is a contradiction between two interacting Activity Systems. We can infer that the contradiction consists in differing objects for some of the students and the lecturer, even though as a collective, the students' objects, when combined, did mostly align with the lecturer's objects. So, it appears that all students were only partially working on the same "problem space" that the lecturer was working on. The Object 3 in Figure 6 signifies that shared aspect of the object which individual students and the lecturer were working on. Recall the second research question of this study:

2) Does the Google Form exercise facilitate discussion between students and students, and students and lecturer, around the core concepts of the seminar?

Four students $(57 \%)$ stated that the Google Form exercise generated discussion between students and students and students and the lecturer around core concepts (refer back to Table 1). One can thus affirm that the tool intervention did facilitate discussion. This finding relates to research which found that face to face discussions that were preceded by computer mediated communication (CMC) were richer and more diverse, as well as studies that show that CMC has benefits for shy or passive students (Asterhan and Eisenmann 2009; Dietz-Uhler and Bishop-Clark 2001; Suler 2004).

\section{DISCUSSION AND CONCLUSION}

This study employed third generation Activity Theory to study the introduction of a new tool, Google Form questions, into postgraduate Economic History seminars. The study located the lecturer and the students' respective objects and described a partial alignment and partial mismatch between the lecturer and the students' objects in the Google Form exercise. It found, further, that Google Forms were considered by all students in the study to be useful in achieving one or more of their objects, and also that Google Forms are an effective way of stimulating discussion in postgraduate Economic History seminars.

So, what do the results of this study and intervention mean for higher education more broadly? First, if the tools are available, this intervention can be tested and adapted in all discussion-based seminars. Second, note that there are good conceptual reasons that the tool intervention can realise a number of its benefits. For instance, a) using the form for students and the educator to gain an overview of where students' conceptions are at in relation to the core content, b) students disclosing their conceptions anonymously in a non-threatening way, 
c) students receiving peer and educator or peer or educator feedback on their conceptions of core content at the outset of the seminar, and d) the educator being enabled to target their contributions to discussions in light of having an overview of the students conceptions - these outcomes are in a way conceptually integral to the tool intervention. Just by undertaking the educational activity, these benefits are realised. Educators are encouraged to try this and cognate interventions in classes where students are disinclined to discuss core content or discussion is patchy and strained. The form or structure of the intervention is stable, so educators who wish to use this intervention need only create Google Form questions that solicit students' conceptions of core content for the seminar or class. The intervention is versatile, has wide application, and is not labour intensive.

Incorporating smartphones and devices into learning scenarios in higher education will only become more widespread. From 2014 to 2017 adults owning smartphones in South Africa increased from 33-56 per cent, and growth trends are similar for other African countries Nigeria 19-32 per cent, Kenya 19-30 per cent, Ghana 15-30 per cent, Senegal 13-34 per cent - over the same period (Pew Research Centre 2018). The University of Johannesburg for example in 2014 made having a smartphone, laptop or handheld device compulsory for 2014 first year students and allocated significant NSFAS funding to this end. The University of Cape Town and Sol Plaatje University have also taken major steps towards seeing that learners have personal mobile learning devices (Brown and Pallitt 2015).

Important recent research into smartphones and learning has found that adolescents in South Africa increasingly see smartphones as tools for social connection, convenience and planning, so much so that the author argues that adolescents see smartphones as a part of their "self" (Davel 2017). This implies that one can anticipate that students coming into South African universities will increasingly already recognise smartphones are tools with a high usevalue. Myriad studies have suggested that students have positive attitudes towards learning with mobile devices (Al-Emran, Hatem and Shaalan 2016). Where this is not so already, smartphones will become as ubiquitous as pens and notepads in universities. Given the deep relationship that we can expect current and future students to have with smartphones and devices as well as the teaching benefits smartphones can have, it is better to acknowledge and integrate smartphones and devices into teaching and learning scenarios than ignore them. It is not envisioned that the intervention analysed in this study will shape the organisation of universities, however a number of micro-level benefits are realised for both students and lectures. These benefits centre around learners and educators having conversations about core content in a way that is targeted at student's conceptions of core content at the outset of discussion seminars. 


\section{REFERENCES}

Al-Emran, M., M. E. Hatem and K. Shaalan. 2016. Investigating attitudes towards the use of mobile learning in higher education. Computers in Human Behavior 56: 93-102.

Asterhan, C. and T. Eisenmann. 2009. Online and face-to-face discussions in the classroom: A study on the experiences of "active" and "silent" students. In CSCL 2009 conference proceedings, 132136.

Barab, S., M. Barnett, L. Yamagata-Lynch, K. Squire and T. Keating. 2002. Using activity theory to understand the systemic tensions characterizing a technology-rich introductory astronomy course. MIND, CULTURE, AND ACTIVITY 9(2): 76-107.

Brown, C. and N. Pallitt. 2015. Personal mobile devices and laptops as learning tools. Moving beyond the hype: A contextualised view of learning with technology in higher education. http://www.cilt.uct.ac.za/sites/default/files/image_tool/images/83/FA_PMDs_final_July 2015.pdf

Czerniewicz, L., A. Deacon, M. Glover and S. Walji. 2017. MOOC - making and open educational practices. Journal of Computing in Higher Education 29(1): 81-97.

Davel, C. 2017. The mobile phone as an extention of the self: A study among adolescents in a secondary school. PhD thesis. University of Cape Town, Cape Town.

Dietz-Uhler, B. and C. Bishop-Clark. 2001. The use of computer-mediated communication to enhance subsequent face-to-face discussions. Computers in Human Behavior 17(3): 269-283. https://doi.org/10.1016/S0747-5632(01)00006-1

Elbow, P. 1988. Writing without teachers. New York: Oxford University Press.

Engeström, Y. 1987. Learning by expanding: An activity-theoretic approach to developmental research. Helsinki: Orienta-Konsultit Oy.

Engeström, Y. 2001. Expansive learning at work: Toward an activity theoretical reconceptualization. Journal of Education and Work 14(1): 133-156.

Engeström, Y. and A. Sannino. 2010. Studies of expansive learning: Foundations, findings and future challenges. Educational Research Review 5(1): 1-24.

Glover, M. 2017. Google Form questions as a stimulus for discussion and interaction in postgraduate Economic History course seminars at a South African university. PGDip essay. University of Cape Town, Cape Town.

Hardman, J. 2005. An exploratory case study of computer use in a primary school mathematics classroom: New technology, new pedagogy? Perspectives in Education: Research on ICTs and Education in South Africa: Special Issue 23(4): 99-111.

Hardman, J. 2008. Researching pedagogy: An activity theory approach. Journal of Education 45(1): $65-94$

Kirkup, G. and A. Kirkwood. 2005. Information and communications technologies (ICT) in higher education teaching - a tale of gradualism rather than revolution. Learning, Media and Technology 30(2): 185-199.

Kuutti, K. 1996. Activity theory as a potential framework for human-computer interaction research. In Context and consciousness: Activity theory and human-computer interaction, ed. B. Nardi, 17-44. Cambridge, MA: MIT Press.

Laurillard, D. 2002a. Rethinking teaching for the knowledge society. EDUCAUSE Review 37(1): 133156.

Laurillard, D. 2002b. Rethinking university teaching: A conversational framework for the effective use of learning technologies. $2^{\text {nd }}$ Edition. London: RoutledgeFalmer.

Murphy, E. and M. Rodriguez-Manzanares. 2008. Contradictions between the virtual and physical high school classroom: A third-generation Activity Theory perspective. British Journal of Educational 
Technology 39(6): 1061-1072.

Murphy, E. and M. Rodriguez-Manzanares. 2014. Activity Theory perspectives on technology in higher education. Hershey, Pennsylvania: IGI Global.

Nardi, B. 1996. Activity theory and human-computer interaction. In Context and consciousness: Activity theory and human-computer interaction, ed. B. Nardi, 7-16. Cambridge, MA: MIT Press.

Peruski, L. 2003. Contradictions, disturbances and transformations: An activity theoretical analysis of three faculty members' experience with designing and teaching online courses. $\mathrm{PhD}$ thesis. Michigan State University.

Peruski, L. and P. Mishra. 2004. Webs of activity in online course design and teaching. ALT-J: Research in Learning Technology 12(1): 37-49.

Pew Research Centre. 2018. Spring 2017 Global Attitudes Survey. Q63, Q64, Q65 \& Q71.

Russell, D. and A. Schneiderheinze. 2005. Understanding innovation in education using activity theory. Educational Technology and Society 8(1): 38-53.

Suler, J. 2004. The online disinhibition effect. Cyberpsychology \& Behavior: The Impact of the Internet, Multimedia and Virtual Reality on Behavior and Society 7(3): 321-326. 


\section{APPENDIX: RESEARCH QUESTIONNAIRE}

1. Did you find that the lecturer gave you enough opportunity to express your views and arguments?

2. Did you find any of the rules or conventions - formal or informal (implicit) - in the seminar or in the course in general were unhelpful for your learning aspirations? If so, can you say why and how the rule(s) could be changed?

3. What in particular did you anticipate or hope you would get from the course overall?

4. In terms of course seminars, what did you hope to achieve or get out of each seminar?

\section{Technology}

Apart from the Vula Learning Management System (LMS), computers, smartphones, tablets, and the venue's monitor, another other digital tools used in the course, there was a class Whatsapp group.

5. In terms of your learning and the course, was the Whatsapp group useful or not useful, and why?

6. Were any other tools besides those noted above used? If so, what tool or tools and how and why did you use them? Please also note how the tool was useful?

\section{Google Forms}

In four of the eight seminars, a Google Form question was provided by the lecturer and a couple of minutes were allocated to answer the question.

7. What did you think the point of the Google Form exercises was?

8. Did you find the Google Form exercise useful? Why or why not?

9. If not useful, do you think the Google Form exercise could be adjusted to make it useful?

10. What do you think the lecturer hoped to achieve with the use of the Google Form exercises in class?

11. What do you think the lecturer's job was after the class submitted their Google Form answers and they were projected onto the monitor in the seminar?

12. What do you think your job was after the class submitted their Google Form answers and they were projected onto the monitor in the seminar?

13. Who determined which Google Form answers were best or most appropriate?

14. Which persons during the course did you find helped you achieve what you wanted out of the course? 